\title{
Safety Threats, Impunity and Professionalism: Journalists' Dilemma in Pakistan
}

\author{
Sadia Jamil \\ School of Communication and Arts, Faculty of Humanities and Social Sciences, the University of Queensland, Brisbane, Australia
}

Copyright $\bigcirc 2018$ by authors, all rights reserved. Authors agree that this article remains permanently open access under the terms of the Creative Commons Attribution License 4.0 International License

\begin{abstract}
This study primarily aims to examine the impact of contextual factors on journalists' safety in Pakistan. The study also analyses the ways safety risks and Pakistan's climate of impunity affect professional journalism in the country. Data have been gathered using the quantitative method of survey and the qualitative method of in-depth interviews. Findings reveal that all surveyed male and female journalists (100\%) view the factors of government's and military's threats and pressure; impunity; the country's socio-political situation and laws, religious extremism and social conservatism as most crucial in affecting their safety. On the other hand, 76\% and $91 \%$ journalists consider a lack of safety training and ineffectiveness of measures as important aspects causing safety risks to them respectively. Drawing on the social responsibility theory, this study suggests that the Pakistani journalists are considerably unable to do 'objective and investigative reporting' freely, truthfully and accurately because of diverse safety threats emerging from internal political and ethnic conflicts; government's, military's and media owners' pressure; law and order situation; religious extremism; conservatism and impunity. Hence, the study questions the notion of media as watch dog and media as the mirror of society in the prevalence of news culture that lacks truthfulness and accuracy. The study invokes for creating professionalism and fostering safe and free journalism necessary for truthful, accurate and impartial reporting in the sake of public's interest and their right to know in Pakistan.
\end{abstract}

Keywords Journalists' Safety, Impunity, Professionalism

\section{Introduction}

Over the past two decades, international organizations monitoring press freedom and media rights have been underlining threats to journalists' safety worldwide. According to Committee to Protect Journalists, more than a thousand of journalists have been killed since 1992, and the killers remained unidentified in the majority of cases especially in non-democratic regimes such as Pakistan. While the high profile cases of Western journalists' killings and kidnapping gain media's attention (such as Daniel Pearl or Marie Colvin), violence against journalists working in conflict areas and non-democratic regions have grown worse. There are countries worldwide (such as Brazil, Mexico, Somalia, Philippine, India, Pakistan, Srilanka, Bangladesh, Syria, Iraq, Afghanistan and Russia) - where threats to journalists' safety have increased due to existing impunity, which indicates that those who are involved in journalists' killings and violence against them are never prosecuted. The impunity for crime against journalists gives an explicit message that silencing journalists is acceptable [1].

The case of Pakistan is complex when analyzing the threats to journalists' safety. Even though the country is much better off than countries such as Iraq, Libya, Syria and Somalia that have torn apart by civil war and internal conflict, Pakistan's numbers of violence against journalists are parallel to these countries. Reports by international organizations have confirmed that the Pakistani journalists work in an unsafe environment where their safety is at stake because of multiple reasons. The point of concern is that the Pakistani journalists confront direct physical and psychological threats across the country, which 'may' affect their ability to practice necessary professional standards (especially truthfulness, accuracy and impartiality). The existing climate of impunity in Pakistan can also pose threat to journalists' freedom - especially for adhering to the principles of truthfulness and accuracy. These facts invoke for a deeper investigation of the issues related to impunity, journalists' safety and professional journalism in the country.

\section{Objectives}

This study aims to investigate the following two objectives: 
- To investigate the impact of eight contextual factors affecting the journalists' safety in Pakistan including: (i) law and order situation; (ii) government's and military's direct or in-direct threats; (iii) risky political and legal environments; (iv) religious extremism, (v) social restrictions and conservatism; (vi) impunity; (vii) journalists' lack of awareness and safety training; and (viii) ineffectiveness or lack of initiatives at various levels (government, media organizations, journalists' unions and individual journalists).

- To analyze the ways safety threats and impunity affect professional journalism in Pakistan.

\section{Literature Review}

\subsection{Social Responsibility Theory and Journalistic Code of Conduct}

Social responsibility theory supports the freedom of press by emphasizing journalists' adherence to professional standards of objectivity, truthfulness, accuracy and impartiality. The theory emphasizes the notion of freedom with responsibility that requires a journalist not only to report facts with truthfulness, but also to provide deeper and unbiased interpretations of a news story in the public's interest. Hence, the theory attempts to buttress journalistic standards and roles in any society for achieving broader goals of democracy and development.

Drawing on the social responsibility theory, many countries worldwide, have devised journalistic codes of ethics [2]. Code of ethics sets a frame work for the journalists within which they can perform their jobs professionally, and thus can be seen as a voluntary and self-regulatory mechanism for responsible journalism [3]. It serves the public interest by ensuring dissemination of fair, impartial, accurate information and protection of other basic human rights such as freedom of speech; protection of privacy, reputation and religious feelings [4].

Interestingly, there is no common model for the codes of ethics in the various regions of the world; however, the ethical principles can be same such as truth, fairness, accuracy and privacy etc. The reason for diversity in codes is basically the difference in the journalistic conventions in the various countries of the world. Another reason is 'societal sensitivities, the 'nature of democracy and environments' that do shape journalistic practices and codes [4]. In the case of Pakistan, safety and impunity have emerged as key factors in defining and shaping journalists' routine practices [5]. It is not known clearly to what extent and how unsafe environment and impunity affect journalists' professionalism in the country. Therefore, this study addresses this question.

\subsection{Issue of Journalists' Safety}

Freedom of expression is considered as a fundamental human right of every individual and the freedom of press is widely viewed as the bedrock of a democratic structure. Media or the press is considered to have special protection for its effective and free operation. This means that individual journalists need be free and safe to perform their journalistic roles. However, the issue of journalists' safety appears to be growing worse with the increasing number of journalists' killings, kidnapping and imprisonment worldwide. There are incidents and threats that affect journalists' ability to exercise their right to freedom of expression as well.

Threats to journalists do come from various corners such as criminals; religious extremists; terrorists; autocratic governments; ethnic, sectarian and mafia groups. In Pakistan, media organizations and the public have also appeared as the sources of threat to journalists [5].

At present, over a dozen of international organisations are working to promote safe journalism and to end impunity for crimes against journalists, among them the United Nations is actively engaged in the problem. Statistics for journalists being killed or attacked are gathered by international organisations such as Article 19; Committee to Protect Journalists (CPJ); Reporters Without Borders (RSF); Freedom House; Inter American Press Association (IAPA); International Federation of Journalists (IFJ); International News Safety Institute (INSI); International Press Institute (IPI); International Freedom of Information Exchange (IFEX); Global Journalists Security and the United Nations Educational, Scientific and Cultural Organisation (UNESCO).

\subsection{Measures of Journalists' Safety}

Some international organisations (such as Committee to Protect Journalists, Reporters without Borders, Freedom House and UNESCO) have well-developed indicators to assess the level of journalists' safety in different regions of the world. Therefore, this section reviews measures of journalists' safety developed by these international organisations.

Committee to Protect Journalists (CPJ) is a New York based organisation that was founded in 1981. As far as the measurement of journalists' killings is concerned, the organisation started to compile the data of journalists' deaths in 1992. CPJ's methodology substantially focuses on impunity and journalists' killings more than any other kinds of threats to their safety [6]. The organisation has developed a set of terminologies to classify the abuses and attacks on journalists such as murders, threats and physical torture. It compiles a 'quantitative data' file every year. This file indicates the number of physical attacks on journalists; the cases of censorship, harassments, intimidations, imprisonment, missing or kidnapping relating to journalists.

The most important aspect of CPJ's assessment is whether the journalist's death was work-related. For this 
purpose, the organisation uses themes of 'motive confirmed' and 'motive un-confirmed' to classify the death. This is quite important aspect to be investigated because journalists' deaths are not work-related all the time, and thus it is highly imperative to assess whether it was a 'personal dispute' which killed them, or it was a journalist's political affiliation which caused his death. In countries like Pakistan, it is difficult to evaluate the motives of journalists' killings clearly because of their political and sectarian affiliations. Therefore, CPJ's criteria of assessing the nature and motive of a journalist's death appear as highly important.

Freedom House is a US based non-profit organisation that has been evaluating press freedom since 1980. Initially, in 1978, the organisation began with publishing a global survey of freedom known as 'Freedom in the World'. Freedom House's press freedom indicators evaluates more broader threats to journalists' safety such as killing, kidnapping, harassment, physical violence, financial risks, political and legal pressures. Thus, the organisation attempts to assess the financial, legal, physical and psychological protections of journalists [7].

Reporters without Borders (RSF) is a non-profit and Paris-based organisation. The organisation evaluates press freedom in all five continents of the world. The organisation measures the level of violence and abuses against journalists working for both traditional (print and broadcast) and new (online) media [8].

More concentrated efforts to end impunity for crime against journalists and to improve the level of journalists' safety worldwide have been made by the United Nations. The UN's 'Plan of Action on Safety of Journalists' has been endorsed by the UN's Chief Executive Board in 2012, which aims to promote safe journalism through mobilizing different stakeholders including UN agencies, governments, governmental bodies, NGOs, media organisations and workers, civil society members and academics. The national level's indicators that evaluate the state of safety issues and collaboration among all stakeholders within a country have been developed from some general indicators of UN's Media Development Indicators (MDI) ${ }^{1}$ and are listed below:

- "Journalists and associated media personnel are not subject to threats, harassment or surveillance.

- Journalists and associated media personnel are not physically attacked, unlawfully detained or killed as a result of pursuing their legitimate activities.

- Media organisations are not forced to close down as a result of pursuing their legitimate activities, or threatened with closure.

1 "In 2008, the Intergovernmental Council of the International Programme for the Development of Communication endorsed the UNESCO Media Development Indicators (MDI): a framework for assessing media development. A short section of these indictors dealt with the issue of journalists'safety." [9: 5]
- $\quad$ Crimes against journalists are prosecuted and there is no climate of impunity.

- Media organisations have policies for protecting the health and safety of their staff and free lancers.

- Measures of social protection are available to all staff, including temporary and freelance employees.

- Journalists do not routinely self-censor because of fear of punishment, harassment or attack.

- Confidentiality of sources is protected in law and respected in practice." [9: 5-6]

At a national level, UN's indicators assess the actions of four groups of actors whose actions can impact on the level of journalists' safety including (i) UN and other intergovernmental bodies functioning directly in a country; (ii) state and political actors; (iii) civil society and academia; (iv) the media and intermediaries. In each category, indicators covers a variety of actions such as: "monitoring safety issues (information collection), promoting norms on safety (which includes the publishing of information, amongst other steps), co-ordination with other actors, training and capacity building programmes, as well as other activities" [9: 7].

At an international level, the United Nations has devised three major indicators, including: (i) "United Nations organisations promote journalists' safety issues at the international level, (ii) international and regional intergovernmental organisations promote journalists' safety issues at the international level, and (iii) international non-governmental organisations promote journalists' safety issues at the international level." As with the indicators for journalists' safety at the national level, the emphasis in these international level indicators is on physical and psychological safeties of journalists, and the related issue of impunity that protects those who commit crimes against journalists from being punished [10: 1].

The review of journalists' safety indicators suggest that CPJ's evaluation of journalists' safety is limited to the assessment of physical threats to journalists and the number of unresolved cases of journalists' killings/or attacks in different countries. Freedom House and Reporters without Borders (RSF) do focus on psychological, legal, digital and financial protections of journalists that are equally imperative to be ensured apart from promoting their physical safety. The UN's 'Plan of Action on Safety of Journalists' is certainly of high importance as it takes a multi-stakeholder and a holistic approach to investigate this crucial issue. The most distinct aspect of the UN's indicators is its broad spectrum to assess the level of journalists' safety and existing impunity at national and international levels [9, 10].

Notwithstanding the importance of indicators developed by abovementioned international organisations, one must consider the diversity of threats to journalists' safety. Most of the indicators developed by the international organisations assess: physical and psychological threats; legal, financial and political pressures; digital risks and 
impunity for crimes against journalists $[1,7,9,10,11]$.

This study takes into account the impact of contextual factors on journalists' safety that is a bit similar to some of the indicators developed by Freedom House and the United Nations. However, the uniqueness of this study is that it offers quantitative and qualitative insights both into the issues of journalists' safety, impunity and professionalism in Pakistan.

\section{Methods}

A total of 100 male and female journalists from five ethnicities (i-e Sindhi, Punjabi, Pashtu, Baluchi and Urdu-speaking) have taken part in the survey research. While the selected journalists are from the most well-known newspapers and television news channels in Karachi (i-e total 22 media organisations), they do have work experience in more than one city of Pakistan. To ensure the variety of feedbacks, this study includes journalists of diverse beats (such as politics, crime, judiciary, defence, sports, business, social and religious affairs, health and education). The study also incorporates 30 in-depth interviews of working journalists (22 male and 8 female) in Karachi, who are full-time employees of selected media organization (see Appendix). The sample of interviewees also includes ten senior journalists working at upper-management positions of director news (for television news channels) and editor-in-chief (for newspapers). All surveyed and interviewed journalists have been selected using purposive sampling ${ }^{2}$. The collected data have analysed thematically ${ }^{3}$ using the

\footnotetext{
2 The purposive sampling refers to the "selection of certain groups or individuals for their relevance to the issue being studied" [12:105) The purposive sampling has been chosen so as to ensure the representation of journalists from five ethnicities (i-e Sindhi, Punjabi, Baluchi, Pashtu and Urdu speaking); religious sects (Shia and Sunni); male and female genders and from print and electronic media both (i-e Urdu and English languages' newspapers and television news channels).

As far as the process of selection is concerned, using purposive sampling, an initial list of 140 journalists was compiled from the selected 22 media organizations in Karachi (see Appendix). Then all of these journalists were contacted through e-mails and telephone calls to have an idea about their: work experience as a journalist, availability and willingness to participate in the study (for survey and interviews) and past experience of participation in any academic research. Then a final list of survey respondents and interviewees was compiled before commencing the data collection. This process took almost two and a half months.

In sect- or ethnicity-based selection, there can be possibility of cultural bias (on the basis of ethnicity or sect). To avoid this, the researcher ensured to recruit almost equal number of journalists from each ethnicity and religious sect for fair representation. In addition, all journalists were provided a project information sheet to explain about: the summary of project, methodology of the study, participants' confidentiality, researcher's and participants' code of conducts (i-e mutual ethics for cultural sensitivity and respect, and appropriate phrasing in questions and answers without compromising on honesty and representation of ideas). Moreover, I also tried to avoid my individual biases or any preexisting idea or assumption/s by constant reevaluation of journalists' feedbacks during the process of data collection and analysis. In addition, this is purely an independent study and thus there is no sponsor bias involved in presentation of findings.

Thematic analysis aims to identify 'themes' or 'patterns' within the qualitative data. It helps to classify data under relevant themes in order to interpret the various aspects of research topic $[13,14,15]$. In this study,
}

research's objectives themes.

\section{Results}

Findings reveal that all surveyed male and female journalists $(100 \%)$ view six factors as most crucial in posing risks to journalists including: (i) the law and order situation; (ii) government's and military's direct or in-direct threats; (iii) risky political and legal environments; (iv) religious extremism, (v) impunity, (vi) social restrictions and conservatism. Additionally $91 \%$ of journalists, in this study, highlight the ineffectiveness or lack of initiatives at the government, media organizations' and journalists' unions' levels as a major cause of threats to them. Many journalists (76\%) see a lack of safety training and awareness among journalists as one of the reasons of growing risks to them. Figure, below, illustrates the impact of contextual factors on journalists' safety in Pakistan.

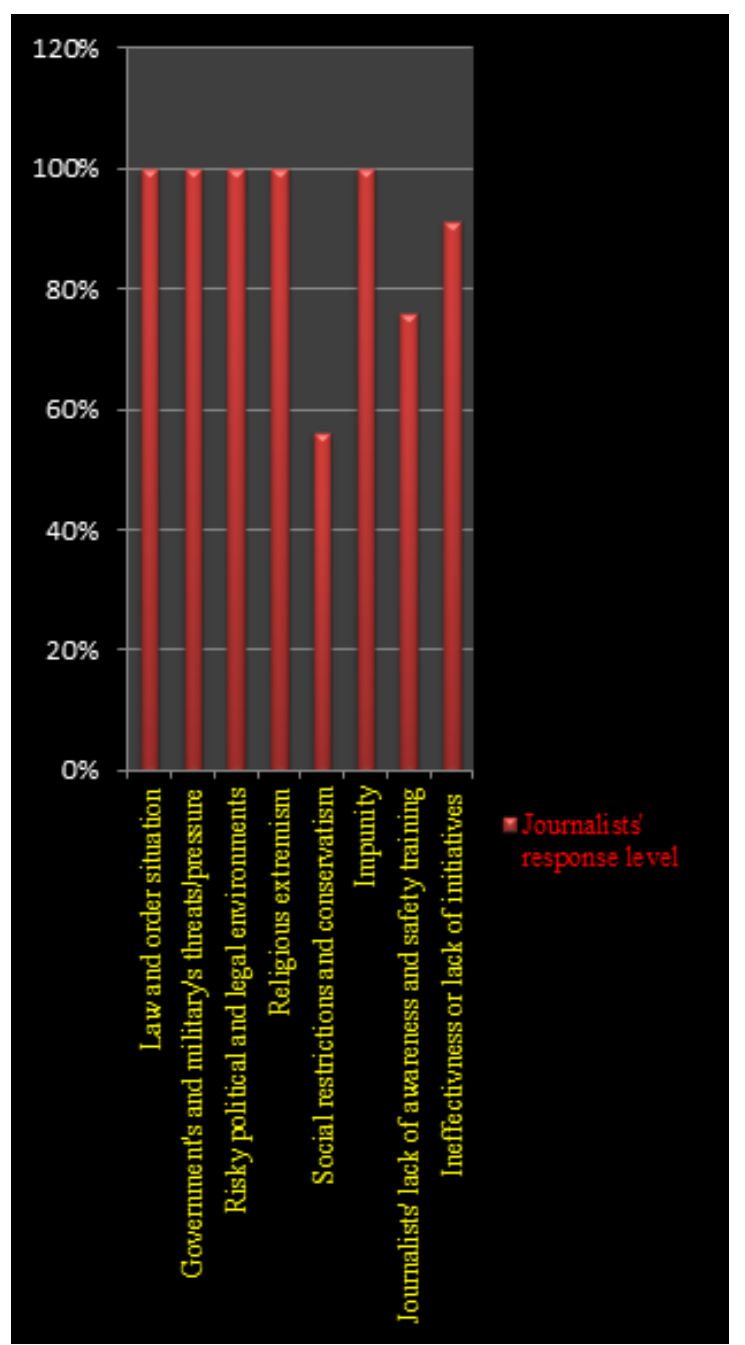

Figure 1. Impact of contextual factors on journalists' safety in Pakistan

the purpose of using thematic analysis is to analyse the large qualitative data systematically under different themes driven from the entire data-set. 
Interview data confirm the survey findings in this study. Interviewees' response suggest that journalists' face physical, psychological and emotional risks because of internal political and ethnic conflicts; government's, military's and media owners' pressure; law and order situation; religious extremism; conservatism and the country's climate of impunity. Markedly, interviewees highlight that it is not mere militants, government, military and Pakistan's socio-political environment that pose risks to them and influence the truthfulness and accuracy of news content. They reveal that media organizations are actually a major source of financial and psychological risks to them and at times they have to self-censor news stories being under pressure of owners' policies and their directives. This implies that professionalism is not merely at stake due to external contextual factors, but journalists' are restrained within their media organizations as well and they are compelled to manipulate facts compromising the accuracy of news stories. The next section discusses these findings in detail.

\section{Discussion}

In the past one decade, journalists' killings around the world suggest that journalism is no more a safe profession and threats to journalists' safety is seriously affecting their right to freedom of expression. Reports by international organisations have revealed the last few years (from 2012 onwards) as the most brutal years in terms of violence against journalists worldwide [16]. Particularly, the situation of Pakistan in terms of violence against journalists is very apprehensive. "According to UN's estimate, at least 71 journalists and media workers have lost their lives since 2001 while pursuing their duties in the country. Consequently, the country has been declared as one of the deadliest places for working journalists in the World." [17:7-8]

This study also confirms that journalists confront immense physical threats and psychological pressure because of county's law and order situation, political environment, laws (especially blasphemy), climate of impunity, religious extremism and social conservatism. Interviewed journalists suggest that those working particularly in the conflict areas of Baluchistan, Khyber Phakhtunistan and Federally Administered Tribal Areas (FATA) are no doubt performing a very risky job. The most obvious physical risk in the conflict areas is that they are in danger of being killed in the crossfire of two opposing forces or terrorists groups. Journalists also face other physical risks of assault, detention and harassment in areas where law and order has broken down and because of government and military. For example, a male interviewee reveals:

Journalism is a very risky profession in Pakistan and journalists can confront threats in any part of the country. However, journalists' physical safety is more at stake in Karachi, Interior Sindh, Federally Administered Tribal Areas, Khyber Phaktunkhwa and Baluchistan provinces. Personally, I think journalists are just not being killed physically, but they are also victim of psychological trauma due to pressure from government, military, political parties and religious organizations. What is worse for journalists is the pressure from their media owners and the society. At times, I have to either censor or change the new stories to please my editor. I do so silently knowing every media organization has its vested interests and affiliations, and most importantly no one likes to lose his or her job............ It is frustrating but the social pressure is more stressful emotionally. People have all means to convey their reaction in form of physical attacks, abusive social media's comments and street protests. I have beaten by the public twice during the coverage of a protest. (Interviewee number 18)

This study finds that government's and intelligence agencies' surveillance not only influence the journalists' information gathering process but also compelled them to restrict their on-duty activities, which ultimately affect the quality of news content. For example, one male interviewee mention:

I have done investigative reporting many years. During Liyari Gang War coverage and Operation Zarb-e-Azab, I could not gather information thoroughly due to heavy restrictions from law enforcement agencies and I had to rely on information from other sources. These are just two examples from my twenty-five years career. When you talk about truth, it is never in its raw form because often we have to rely on second-hand-information (from other sources) or information provided by the government's and military's sources........... Let me tell you that male journalists constantly face physical, psychological and financial risks in Pakistan. Nevertheless, for female journalists, the profession is perhaps challenging in other ways due to gender-based risks and social conservatism. (Interviewee number 16)

These findings are not surprising given the violent and fearful environment of Pakistan. International organisations monitoring press freedom regularly highlight the incidents of journalists' killings, kidnapping, attacks and imprisonment in the country. In most incidents, investigative journalists are attacked and it is always difficult to accuse any particular group or institution directly in Pakistan. For example, in September 2010, Umer Cheema, an investigative journalist of The News, an English daily newspaper with a nationwide coverage, was attacked and physically tortured by unknown attackers. This was a serious case of violence because the victim was parade naked with shaved eyebrows, and sadly the attackers remained unidentified [14]. Subsequently to this incident, the assassination of Asia Times' Online 
correspondent Saleem Shehzad, in May 2011, was another case that caught the attention of international organisations protecting journalists' rights worldwide. It was reported that Saleem was assassinated for his critical and investigative reports against some state's institutions [15].

Moreover, the murder of Wali Khan Barber was another major incident of target-killing in 2011. Wali Khan Babar was a Karachi-based journalist of Geo Television News Channel. In April 2014, Hamid Mir, a senior journalist of Geo News (a private television news channel), was attacked by unknown assailants in Karachi. Mir survived the injury of six bullets in the assassination's attempt. More recently, in December 2015, Zaman Meshud, a reporter for a daily Urdu newspaper 'Umet' and SANA news agency, was killed by terrorists. Zaman was also President of Tribal Union of Journalists' South Waziristan and district coordinator for the Human Rights Commission of Pakistan $[18,19]$.

The aforementioned cases are only a few examples of how local journalists' suffer violence and attacks in Pakistan, especially for their investigative reports. It must be mentioned that physical risks are not only a challenge for the Pakistani journalists, but also for international journalists working in the country. It is worthwhile to quote here the murder of Wall Street Journal's reporter, Daniel Pearl, who was kidnapped and later assassinated in 2002 in the Southern port city of Karachi. In the same year, four local people were sentenced for the assassination of Daniel Pearl, especially when Pakistan's government confronted immense international pressure. A report by Amnesty International [20] highlights the level of journalists' safety working for foreign media in Pakistan. The report reveals:

In recent years, all foreigners based in Pakistan, including journalists, have had their travel through the country drastically curtailed by the authorities' often ad hoc application of travel and visa restrictions. Some journalists are restricted to one or more cities and all are excluded from carrying out unauthorised travel to dangerous and politically sensitive areas like Baluchistan, the Federally Administered Tribal Areas (henceforth 'the Tribal Areas') and interior Sindh. The authorities have increasingly required foreign journalists to apply for No Objection Certificates (NOCs) before visiting these areas..........................Foreign journalists are generally immune from direct harassment or abuse from the ISI or other state's security personnel. 'There are two thin layers of protection as a foreign journalist in Pakistan. First, you work for a foreign organisation. Second, you are a foreign national,' one Islamabad based foreign correspondent told Amnesty International. However, on some rare occasions even foreign journalists have fallen victim to threats and attacks. [20: 23]

The more bad news about the country is the existing impunity for crimes against journalists and the number of unresolved cases of their killings. Except of Daniel Pearl's and Wali Khan Babar's murder cases, in most of the mentioned cases, attackers are still unidentified and have not been trailed by the court. The climate of impunity in Pakistan clearly indicates the country's government and law enforcement agencies' failure to investigate the cases of journalists' killings and attacks. The environment of impunity and violence has not only spawned physical and psychological risks for the Pakistani journalists, but it has also affected the quality of journalism given neither journalists are able to exercise their right to freedom of expression nor the public is having the information freely that they should receive. According to one interviewee:

Journalists' do not have freedom of expression in Pakistan. We cannot write fearlessly and even facts are self-censored often by virtue of threats and pressure from various corners. Government, military, political parties, religious groups and even public all are sources of threats and pressure............. Pakistan's laws pose chilling effect on the free speech right too........... I would like to mention some laws that are problematic in terms of their legal provisions and possible abuse like Blasphemy laws (1860), Official Secrecy Act (1923) and Defamation Ordinance (2002)........ The worse aspect is Pakistan's culture of impunity. Criminals are hardly prosecuted for their committed crime and it is an individual's luck to have justice, if they are trailed. (Interviewee number 12)

This study manifests the silencing of Pakistan's journalists through killings and violence that has resulted in a climate of fear in country and journalists' compulsion to self-censor news content, indicating that the society is deprived of "journalistic contribution" and informed citizenry through accurate and truthful information. Hence, efforts should be made to promote safe journalism and to end the problem of impunity considering its implications at individual journalistic and broader societal levels in Pakistan.

Interestingly, in this study, interviewed journalists' response highlights that safety risks to journalists are not only posed by certain contextual factors, but media organizations' also cause psychological, emotional and financial risks ${ }^{4}$ to them. Some interviewed journalists assert that they censor facts to safe their jobs. For example, according to a male interviewee from a private television news channel:

\footnotetext{
4 "Psychological risks here refer to mental stress, trauma and pressure that may affect a journalist's ability to perform his/her job freely and safely. Financial risks mean the threats of job insecurity, pay-scale disparity and forced job termination. Emotional risks include the risks of anxiety, fear, depression, offence and lower self-esteem that mainly arise from the country's social context or a journalist's surrounding environment (i.e., workplace's environment and socio-political environment)" [5].
} 
It is usually opined that government, military and cultural and political environments influence the truth and journalists' right to freedom of expression in Pakistan. People hardly see how media owners insult journalists, restrain their freedom and pursue them to manipulate facts and censor news stories for their vested interests. I have experienced forced job termination and immense mental trauma once because I could not compromise on my journalistic independence.............It is not just a bullet that kills a person. Psychological and emotional risks kill a person mentally, and this is happening to many Pakistani journalists who are suffering in silence (Interviewee number 21).

These findings indicate that the notions of truth and accuracy struggle to find its space in Pakistan's journalism as journalists are forced to filter and alter facts. On the contrary, some journalists in this study highlight that journalists' political and religious affiliations do affect their professionalism. A female interviewee state, "we cannot put the onus of responsibility on government or army or media owners. One must look at how journalists manipulate facts by virtue of their individual political and religious inclinations, and this could be risky for them" (Interviewee number 4). I think debates around journalists' safety risks are mostly focused on macro-level sources of threats and largely ignore how individual journalists can affect their professionalism and can pose threat to them by being impartial. Therefore, it is imperative to evaluate macro and micro-levels factor both when analysing safety of journalists in Pakistan, thereby to have more inclusive safety mechanism in the country.

Furthermore, the review of journalists' safety indicators developed by the United Nations and press freedom indicators devised by Freedom House and Reporters Without Borders suggest that these organisations do emphasise physical, psychological, legal, financial and digital protections of journalists. At a national level, as confirmed by this study, there are very limited efforts to encounter threats to journalists' safety either online or offline by Pakistan's government, media organisations and journalists' unions (see also Section 4). Noticeably, some local and international organisations have taken positive initiatives to promote safe journalism in Pakistan such as:

- The UN's Plan of Action on Safety of Journalists to promote safe journalism.

- The development of a safety guidebook for the Pakistani journalists that guides about how to stay safe and professional in Tribal area and Khyber Phuktunkhwa.

- The establishment of 'Muhafiz' that is a digital tool to report threats to journalists and the media. This is a project that was initiated by Media Matters for Democracy (MMfD) in collaboration with Code for Pakistan, Peshawar Press Club and National Press Club Islamabad [21, 22].
- The establishment of Pakistan's Journalists' Safety Fund to help the victimized journalists and their immediate families.

- The establishment of Trauma and Competence Centre by Peshawar University's Departments of Journalism and Psychology.

The abovementioned initiatives are indeed significant [23]. Nevertheless, given the diversity of threats faced by the Pakistani journalists and its adverse effects on their professionalism, there is a an urgent need to have a safety mechanism that not only serve to improve journalists' safety level and encounter the problem of impunity, but at the same time that recognize 'safety' as a prerequisite of professional journalism (based on the principles of journalistic freedom, truthfulness, accuracy and impartiality).

\section{Conclusions}

This study confirms substantial influence of contextual factors on journalists' safety in Pakistan. Findings explicitly suggest that not only journalists' physical, psychological, emotional and financial well-beings are at stake, but the quality of journalism and professional standards are at risk too due to diverse threats posed to journalists. The Pakistani journalists employ self-censorship to report on news stories and compromise on the principles of objectivity, truthfulness and accuracy mainly because they don't want to be victim of threats from various sources (either government or military or militants or political parties or religious groups or media owners). In such circumstances, can Pakistan's media be viewed as watchdog or mirror of the society? The answer is indeed, No! Thus, this study emphasises government's, media organizations' and journalists' unions' collective actions for promoting safe and free journalism that is indispensable for truthful, accurate and impartial reporting in the sake of public's interest and their right to know in Pakistan. Additionally, this study invokes for further research on how journalists' political and religious affiliations affect their safety and professional journalism in the country.

\section{Appendix}

This study includes male and female journalists from eleven Urdu language's television news channels and ten Urdu and English languages' newspapers. The list of selected television news channels is as under:
1. Geo Television News
2. ARY News
3. SAMMAA News
4. AAJ New
5. Express News
6. Dawn News
7. Aab Tak News 
8. Dunya News

9. News 92

10. Jaag TV

11. Pakistan Television Network (PTV - Karachi News)

The list of Urdu language's newspapers is as under:

1. Daily Jang

2. Nawa-e-Waqt

3. Daily Express

4. Daily Ummat

5. Daily Jurat

6. Daily Khabrain

The list of English language's newspapers is as under:

1. Daily Dawn

2. The News International

3. Express Tribune

4. The Nation

5. Business Recorder

\section{REFERENCES}

[1] Committee to Protect Journalists Impunity Index. 2017. Available from: https://cpj.org/tags/impunity-index-2017

[2] Baran J, Davis D. Mass Communication Theory. USA: Wadsworth Publishing Company; 2005.

[3] Encabo M.N. The Ethics of Journalism and Democracy. European Journal of Communication 1995; 10 (4): 513-526

[4] Bayder Y. Setting up a Journalistic Codes of Ethics: The core of media self-regulation; 2008. Media Self-Regulatory Guide (OSCE). Available from: http:// www.osce.org./f

[5] Jamil S. Freedom under pressure? Threats to journalists' safety in Pakistan. In: Carlsson U, Poyhtari R, editions. Assault on Journalism. Gothenburg: NORDICOM; 2017

[6] Committee to Protect Journalists. Methodology; 2017. Available from: https://cpj.org/data/methodology/

[7] Freedom House. Methodology for assessing the freedom of press; 2017. Available from:

https://freedomhouse.org/report/freedom-press-2017-meth odology

[8] Reporters without Borders. Methodology; 2017. Available from: https://rsf.org/en/detailed-methodology

[9] UNESCO. Journalists' Safety Indicators: International Level - Based on the UNESCO's Media Development Indicator; 2013.

Available from: http://www.unesco.org/new/en/communica tionand-information/freedom-of-expression/safety-of-journ alists/journalists-safety-indicators

[10] UNESCO. Journalists' Safety Indicators: International Level - Based on the UNESCO's Media Development Indicator; 2013.
Available from: http://www.unesco.org/new/en/communica tionand-information/freedom-of-expression/safety-of-journ alists/journalists-safety-indicators/

[11] Freedom House. Freedom of the Press Report; 2016. Available from: https://freedomhouse.org/report/freedom-press/2016/pakista $\mathrm{n}$

[12] Gray, P.S, Williamson, J.B, Karp, D.A, Dalphin, J.R. The research imagination: An Introduction to qualitative and quantitative methods. New York, NY: Cambridge University Press; 2007.

[13] Boyatzis, R.E. Transforming qualitative information: Thematic analysis \& code development. Thousand Oaks, CA: Sage Publications; 1998.

[14] Braun, V., Clarke, V. Using Thematic Analysis in Psychology. Qualitative Research in Psychology 2008; 3 (2): 77-101. Available from:

http://www.tandfonline.com/doi/pdf/10.1191/1478088706q p063oa

[15] Stirling, A.J. Thematic networks: an analytic tool for qualitative research. Qualitative Research 2001; 1: 385-405. Available from:

http://qrj.sagepub.com/content/1/3/385.full.pdf + html

[16] 71 journalists killed in Pakistan since 2001: report. The News 2015 November 2. Available from: http://www.thenews.com.pk/latest/9553-71-journalists-kille d-in-pakistan-since-2001-report

[17] Jamil S. Freedom of expression and journalists' safety: An analysis of conflict reporting and peace journalism education in Pakistan. Journal of the Association of Journalism Education 2017; 6 (2): 7-16.

[18] Cheema U. Abducted and tortured - for reporting the News, The Wall Street Journal; 2010 October 13. Available from: http://online.wsj.com/articles/SB100014240527487037941 04575545914180906100

[19] Committee to Protect Journalists. Baluchistan latest epicentre of attacks on Pakistani press; 2012. Available from: http://cpj.org/blog/2012/10/baluchistan-latest-epicenter-of-a ttacks-on-pakista.php

[20] Amnesty International. A Bullet Has Been Chosen For You: Attacks On Journalists In Pakistan; 2014. Available from: https://www.amnesty.org/en/documents/asa33/005/2014/en/

[21] International News Safety Institute. Journalism Safety: Threats to Media Workers and Measures to Protect Them; 2013. Available from:

http://www.newssafety.org/uploads/Good\%20Practice $\% 20$ INSI $\% 20$ Final $\% 20 \mathrm{Feb} 2014 . p d f$

[22] Safety for journalists: First ever digital threat-reporting system. The Express Tribune 2015 November 27. Available from:

http://tribune.com.pk/story/999223/safety-for-journalists-fir st-ever-digitalthreat-reporting-system/

[23] International Journalists' Network. Pakistani media leaders' compiles list of safety recommendations for journalists; 2015. Available from:

https://ijnet.org/en/blog/pakistani-media-leaderscompile-list -safety-recommendations-journalists 